Article

\title{
Investigation of the Thermal Properties of Electrodes on the Film and Its Heating Behavior Induced by Microwave Irradiation in Mounting Processes
}

\author{
Kenji Kanazawa $^{1}{ }^{(}$, Takashi Nakamura ${ }^{2}\left(\mathbb{D}\right.$, Masateru Nishioka ${ }^{2}$ and Sei Uemura ${ }^{1, *}$ \\ 1 Sensing System Research Center (SSRC), National Institute of Advanced Industrial Science and \\ Technology (AIST), 1-1-1 Higashi, Tsukuba, Ibaraki 305-8565, Japan; kenji.kanazawa@aist.go.jp \\ 2 Research Institute for Chemical Process Technology, National Institute of Advanced Industrial Science and \\ Technology (AIST), 4-2-1, Nigatake, Miyagino-ku, Sendai 983-8551, Japan; nakamura-mw@aist.go.jp (T.N.); \\ m-nishioka@aist.go.jp (M.N.) \\ * Correspondence: sei-uemura@aist.go.jp
}

Received: 2 April 2020; Accepted: 5 May 2020; Published: 9 May 2020

check for updates

\begin{abstract}
We have developed a novel microwave (MW) soldering system using a cylindrical single-mode $\mathrm{TM}_{110} \mathrm{MW}$ cavity that spatially separates the electric fields at the top and bottom of the cavity and the magnetic field at the center of the cavity. This MW reactor system automatically detects the suitable resonance frequency and provides the optimum MW irradiation conditions in the cylindrical cavity via a power feedback loop. Furthermore, we investigated the temperature properties of electrodes by MW heating with the simulation of a magnetic field in the $\mathrm{TM}_{110}$ cavity toward the mounting of electronic components by MW heating. We also developed a short-time melting technology for solder paste on polyimide substrate using MW heating and succeeded in mounting a temperature sensor using the novel MW heating system without damaging the electronic components, electronic circuits, and the substrate.
\end{abstract}

Keywords: electronics package; induction heating; magnetic field; electric field; $\mathrm{TM}_{110}$ single-mode cavity; solder; eddy current

\section{Introduction}

The Internet of Things (IoT) applications include smart grids, smart homes [1], sensors [2,3], and actuators [4]. Their applications are remotely accessible and enable the exchange of information, allowing for the control of electrical devices and monitoring healthcare from anywhere on the network. This multifunctionality has seen the IoT receive considerable attention in an attempt to revolutionize our lifestyles [5,6]. In smart sensors and actuators, technological developments in mounting electronic components on a flexible substrate (such as textile, plastic substrates, and stretchable thermoplastic elastomer resins) are urgently required [2,3]. However, the heating process used in conventional industrial solder mounting (i.e., heating by reflow oven) requires temperatures of more than $170{ }^{\circ} \mathrm{C}$ for about $300 \mathrm{~s}[7,8]$, which means that the glass transition temperature $\left(\mathrm{T}_{\mathrm{g}}\right)$ of flexible substrates such as polyethylene terephthalate $\left(\mathrm{PET}, \mathrm{T}_{\mathrm{g}}=120^{\circ} \mathrm{C}\right.$ ) and polyethylene naphthalate $\left(\mathrm{PEN}, \mathrm{T}_{\mathrm{g}}=140^{\circ} \mathrm{C}\right)$ should be higher than this if conventional industrial solder mounting systems are to be used. Hence, it is impossible to mount components on flexible and/or stretchable substrates that have low thermostability using solder as a connection material.

To resolve the temperature problems, electrically conductive adhesives and heating processes (electronic packaging technology), which serve as electric and thermal conductors as well as mechanical connectors without heat damage, are important (Figure 1). Despite the development of polymer-based conductive adhesives based on polymers with a lower melting point than solder paste [9], the bond 
strength and conductivity are lower than those of solder paste, and so this approach has not been adopted. Thus, a new solder paste with low melting point, high conductivity, and strong adhesion force between the electronic components and substrates is strongly required.

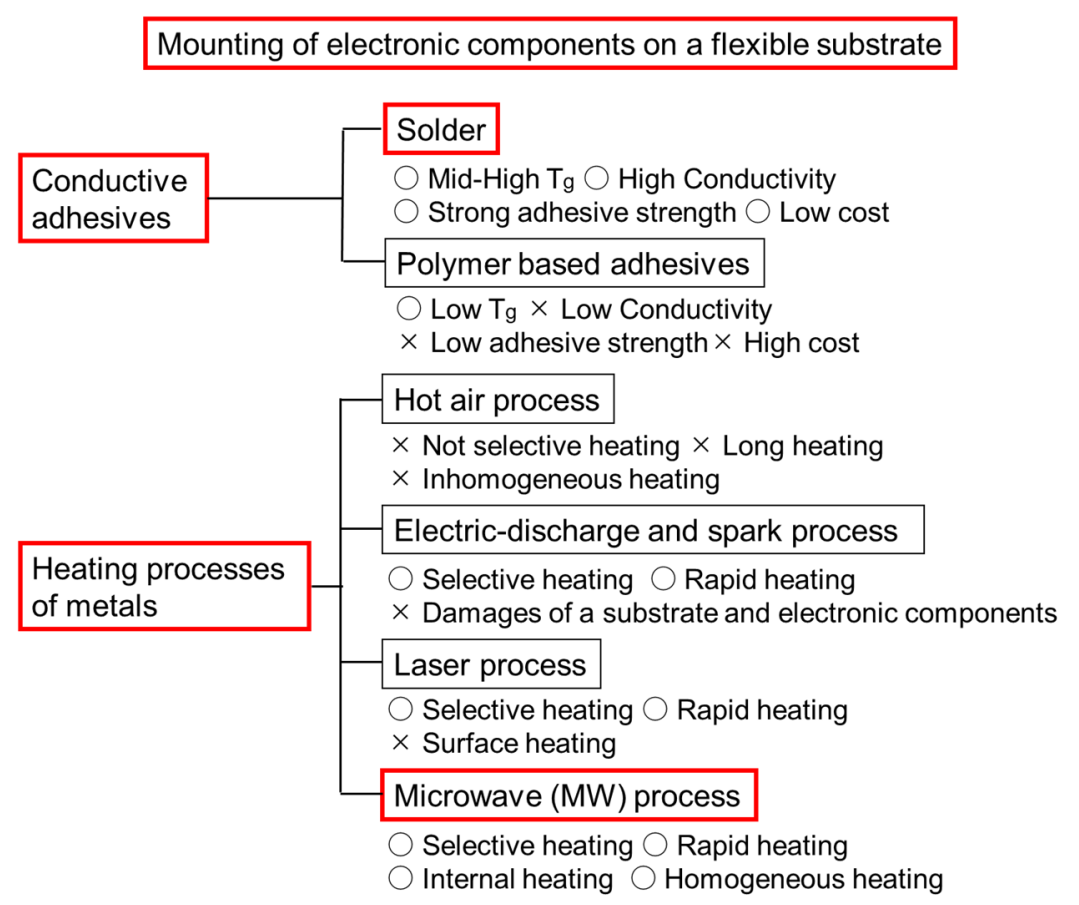

Figure 1. Candidates for conductive adhesives and heating processes of metal in mounting of electronic components on flexible substrate. Circle marks $(\bigcirc)$ and cross marks $(\times)$ mean desirable and undesirable properties in the mounting processes of electronic components on flexible substrate, respectively. Red squares highlight the focuses of this study.

Regarding the heating process of metal, various methods using lasers [10,11], electric-discharge [12], and microwave (MW) [13,14] techniques have been reported. Although selective laser sintering (SLS) was developed by Dechkard [15] and has been widely utilized by industry, understanding chemical, mechanical, and material metallurgical phenomena in SLS process was difficult. Electric-discharge techniques enable rapid heating. Chaim reported that the spark plasma sintering (SPS) process demonstrates sintering, consolidation and crystal growth by spark plasma systems [16]. Among the methods of metal sintering, MW-based techniques particularly represent a powerful approach because MW can selectively heat materials. Heating by MW is based upon the ability of materials to absorb and transform electromagnetic energy into heat. Materials are classified into three categories, with respect to their interaction with MW. (a) MW reflectors (high conductive materials such as metals); the material is not effectively heated by MW. (b) MW transmitters (low loss insulator materials such as Teflon and quartz); MW can penetrate through the material without any absorption, losses or heat generation. (c) MW absorbers (high loss insulator such as dielectric materials); they take up the energy from the MW field and get heated up rapidly [14,17,18]. So far, MW dielectric heating has been used for inorganic/organic syntheses [19-21] and metal nanoparticle synthesis [22,23]. Bulk metals cannot be heated by an electric field because the spark phenomenon occurs as follows. When MW interacts with a bulk metal, the electrons on the material's surface get sloshed around. If the metal has an edge, the charges can pile up and result in a high concentration of voltage. If the voltage is high enough, it can rip an electron off a molecule in the air, leading to creating a spark. Therefore, the electric field and magnetic field are separated from each other, and the heating process by a magnetic field is needed to heat metal without spark generation. Various MW-assisted reactors are commercially available for application; however, the most commercial MW reactor is a multi-mode reactor and the electromagnetic distributions dramatically changes when materials are set in the 
reactor and metals cannot be heated during controlling the electromagnetic distributions, causing the inhomogeneous heating of the reactor [22,23]. Hence, an applicator with a multi-mode reactor is generally used for the continuous vulcanization of rubber, heating food, and heating of dielectric materials. On the other hand, an applicator with a single-mode is suitable for the heating of a metal because electromagnetic distributions can be controlled during MW irradiation. However, MW reactor systems with a cylindrical single mode cavity are scarce.

In this study, we focused on an MW sintering system to mount electronic components on substrates with low thermostability. We originally developed an MW reactor system that separates the electric fields at the top and bottom and the magnetic field at the center in a cylindrical single-mode MW cavity. This MW reactor system automatically detects the suitable resonance frequency and provides the optimum MW irradiation conditions in the cylindrical cavity via a power feedback loop, leading to the generation of standing wave in the center of the MW cavity. Consequently, a homogeneous heating zone can be created along the central line of the MW cavity. In this paper, we describe the heating property of the electrode pad shape effect by MW that was prepared by silver paste screen printing and the mounting of a thermo-sensor device on polyimide substrate using MW in a magnetic field without damaging the sensor or the substrate. Furthermore, the results of thermogravimetric (TG), differential thermal analysis (DTA), and differential scanning calorimetry (DSC) are performed to evaluate the decomposition behavior of the solder paste.

\section{Experimental Section}

\subsection{Materials}

Conductive silver paste (REXALPHA RA FS 074, Toyochem Co. Ltd., Tokyo, Japan) and solder paste (L20-BLT5-T7F, Sn42.0/Bi58.0 (in wt.\%), melting point: $138{ }^{\circ} \mathrm{C}$, Senjyu Metal Industry Co., Ltd., Tokyo, Japan) were used as received without further addition of solvent and flux. Scotch tape (standard $3 \mathrm{M}$ brand transparent tape with a thickness of $52 \mu \mathrm{m}$ ) was used to prepare the solder paste samples. A thermo-sensor (SHT31-DIS-B, size: $2.5 \mathrm{~mm} \times 2.5 \mathrm{~mm} \times 0.9 \mathrm{~mm}$, SENSIRION Corp., Zurich, Switzerland) for mounting by MW irradiation was used. As references, SHTDA2 (SENSIRION Corp., Zurich, Switzerland) with an SHT35 thermo-sensor (SENSIRION Corp., Zurich, Switzerland) and a digital thermo-meter (Vaisala, Vantaa, Finland) were used.

\subsection{Preparation of Samples and the Induction Soldering Method by MW}

2.2.1. Preparation of Silver Paste Pad for the Investigation of the Pad Shape on Induction Soldering by MW and the Induction Soldering Method by MW

Samples for the investigation of pad shape effect with silver paste on induction soldering by MW were prepared by screen printing machine (NT-15TVA, Neotechno Japan Corp., Tokyo, Japan) with a squeeze speed of $20 \mathrm{~mm} / \mathrm{s}$ on polyimide sheet substrate, followed by heating with a hot plate at $150{ }^{\circ} \mathrm{C}$ for $20 \mathrm{~min}$ (the sizes given in Table S1).

To investigate the pad shape effect on induction soldering by MW, the prepared pads were mounted coaxially at the center of the $\mathrm{TM}_{110}$ cavity and heated by MW at 1, 5, 10, 20, and $30 \mathrm{~W}$ of output powers for $30 \mathrm{~s}$ under the atmosphere, respectively.

2.2.2. Preparation of Samples for Investigation of Solder Heating Behavior by the Induction Soldering of MW and Induction Soldering by MW

The samples of solder paste for MW sintering tests were prepared using the blade cote method. First, a $1 \mathrm{~cm} \times 1 \mathrm{~cm}$ square of scotch tape with a thickness of about $60 \mu \mathrm{m}$ was formed on a $3 \mathrm{~cm} \times 3 \mathrm{~cm}$ polyimide sheet. Second, solder paste was spread using a slide glass and the scotch tape was removed (Figure S1). 
To investigate solder heating behavior by MW, the prepared samples were mounted coaxially at the center of the $\mathrm{TM}_{110}$ cavity and heated by MW with 1, 5, 10, 20, and $30 \mathrm{~W}$ output powers for $70 \mathrm{~s}$ under the atmosphere. The cooling times of the samples were less than $20 \mathrm{~s}$.

2.2.3. Preparation of Samples for Mounting Electric Components by the Induction Soldering of MW and Induction Soldering by MW

The circuit patterns of silver paste were prepared by a screen printing machine (NT-15TVA, Neotechno Japan Corp., Tokyo, Japan) with a squeeze speed of $20 \mathrm{~mm} / \mathrm{s}$ on polyimide sheet substrate, followed by heating with hot plate at $150{ }^{\circ} \mathrm{C}$ for $20 \mathrm{~min}$. Solder paste was also printed on the circuit patten. After this, thermo-sensor was placed on the solder paste.

To package the electronic component by MW, the prepared samples were mounted coaxially at the center of the $\mathrm{TM}_{110}$ cavity and heated by MW with $1 \mathrm{~W}$ of output power for $40 \mathrm{~s}, 5 \mathrm{~W}$ of output power for $22 \mathrm{~s}, 10 \mathrm{~W}$ of output power for $11 \mathrm{~s}, 20 \mathrm{~W}$ of output power for $8 \mathrm{~s}$, and $30 \mathrm{~W}$ of output power for $4 \mathrm{~s}$ under the atmosphere, respectively. The cooling time of samples were less than $20 \mathrm{~s}$.

\subsection{MW Sintering System}

The MW reactor system (Ryowa Electronics Co., Ltd, Miyagi, Japan) consists of a variable-frequency microwave generator $(2.45 \pm 0.05 \mathrm{GHz}, 200 \mathrm{~W})$ and a cylindrical single-mode cavity (Figure 2). As shown in Figure $2 \mathrm{~b}$, the inner diameter of the $\mathrm{TM}_{110}$ single-mode cavity was designed based on the incident electromagnetic wave frequency $(2.45 \mathrm{GHz})$. The inner diameter and height of the cavity were $14.6 \mathrm{~cm}$ and $11.0 \mathrm{~cm}$. Samples were mounted coaxially at the center of the $\mathrm{TM}_{110}$ cavity. The distance between the sample and microwave antenna was $13.45 \mathrm{~cm}$. The oscillation frequency was monitored for matching with the resonance frequency. The applied power was controlled by the temperature feedback module. The surface temperature of samples was measured using an infrared (IR) thermal camera (Model PI-200, Optris GmbH, Berlin, Germany) placed through the open circular slit $(1.5 \mathrm{~cm}$ diameter) of the cavity.

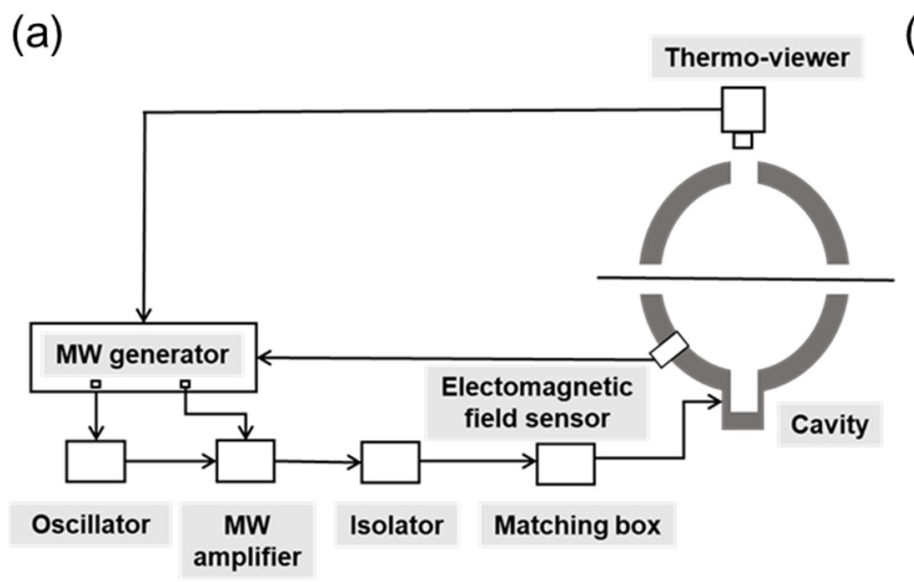

\section{(b)}

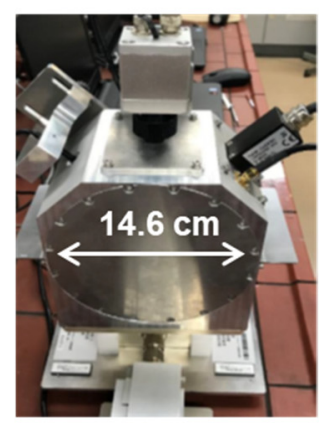

Figure 2. (a) Induction soldering system of microwave (MW) and (b) $\mathrm{TM}_{110}$ single-mode cavity.

\subsection{Electromagnetic Simulation in $T M_{110}$ Mode Cavity with and without Bulk Silver}

The electromagnetic field distribution in cavity was determined by the finite element method (FEM) simulations performed using COMSOL Multiphysics ${ }^{\circledR}$ software (version 5.4, 2018, COMSOL Inc., Boston, MA, USA). The simulation module included the MW antenna and the elliptical cavity with 15.8-cm inner diameter and an 8.0-cm height. The base of the antenna was set to the lumped port that introduced the electromagnetic wave. The walls of the elliptical cavity and the MW antenna were made of aluminum and used as the impedance boundary condition. The numerical model for the simulation of the electromagnetic field is described below: 


$$
\nabla \times\left(\mu_{r}^{-1} \times E\right)-k_{0}^{2}\left(\varepsilon_{r}-\frac{j \sigma}{\omega \varepsilon_{0}}\right) E=0
$$

where $\mathrm{E}$ denotes the electric field vector inside the cavity, $\mu_{r}$ the relative permeability, $j$ the imaginary unit, $\sigma$ the conductivity, $\omega$ the angular frequency, and $\varepsilon_{0}$ the permittivity. The model used material parameters for air: $\sigma=0, \mu_{r}=\varepsilon_{r}=1$. In the bulk silver with a thickness of $8 \mu \mathrm{m}$, the same parameters were used except for the conductivity, which was $61.6 \times 10^{6} \mathrm{~S} / \mathrm{m}$. The FEM mesh configurations, such as the number of elements and time of solving, are summarized in Table S2.

\subsection{Instruments}

The thermal characteristics of the solder paste were measured by differential thermal analysis (DTA, TG/DTA6200, Seiko Instrument Inc., Chiba, Japan), thermogravimetry (TG, TG/DTA6200, Seiko Instrument Inc., Chiba, Japan), and differential scanning calorimetry (DSC, EXSTAR DSC 7020, Seiko Instrument Inc., Chiba, Japan) at a heating rate of $5{ }^{\circ} \mathrm{C} / \mathrm{min}$ in air. Optical images of the sample were recorded on a VW-9000/VW-600c digital microscope (Keyence Corp., Osaka, Japan).

\subsection{Method of Measuring Room Temperature}

The room temperature was measured using the thermo-sensor mounted by the induction soldering of MW. To convert from voltage to temperature, the following expression, which is defined by supplier of a temperature sensor (SysCom. Inc., New York, NY, USA), was used:

$$
\text { Temperature }(\%)=(\text { output voltage } \times 1000 / 25)-40
$$

The input voltage was applied using a direct current (DC) signal source (SS7012, Hioki E.E. Corp., Nagano, Japan), and the output voltage was obtained using a multi-input data recording system (NR-600, Keyence Corp., Osaka, Japan). Furthermore, a temperature sensor (SHTDA-2, SysCom. Inc., New York, NY, USA) was used as a reference, because the sensor mounted by MW was a type of SHTDA-2 sensor.

In addition, a digital thermo-meter (HM41, Vaisara, Vantaa, Finland) was employed as a reference to check the room temperature.

\section{Results and Discussion}

\subsection{Induction Soldering System by MW}

Metals cannot be heated by MW in an electric field because sparks occur. Therefore, we originally developed a frequency-controlled MW system that can compensate for shifts in the resonance frequency through automatic detection and tracking, and which can then feedback the best condition for MW irradiation. Consequently, a strong magnetic field was uniformly formed along the central line of the cavity, where $90^{\circ}$ is the angle direction of sample conveying direction (Figure 3). To confirm whether the spark phenomenon occurs or not using the developed induction soldering system of MW, we tried to heat metals by MW in a magnetic field. As the result, metal was successfully heated without causing the spark phenomenon. From this result, we found that the sample could be heated by the magnetic field of MW. 
(a)

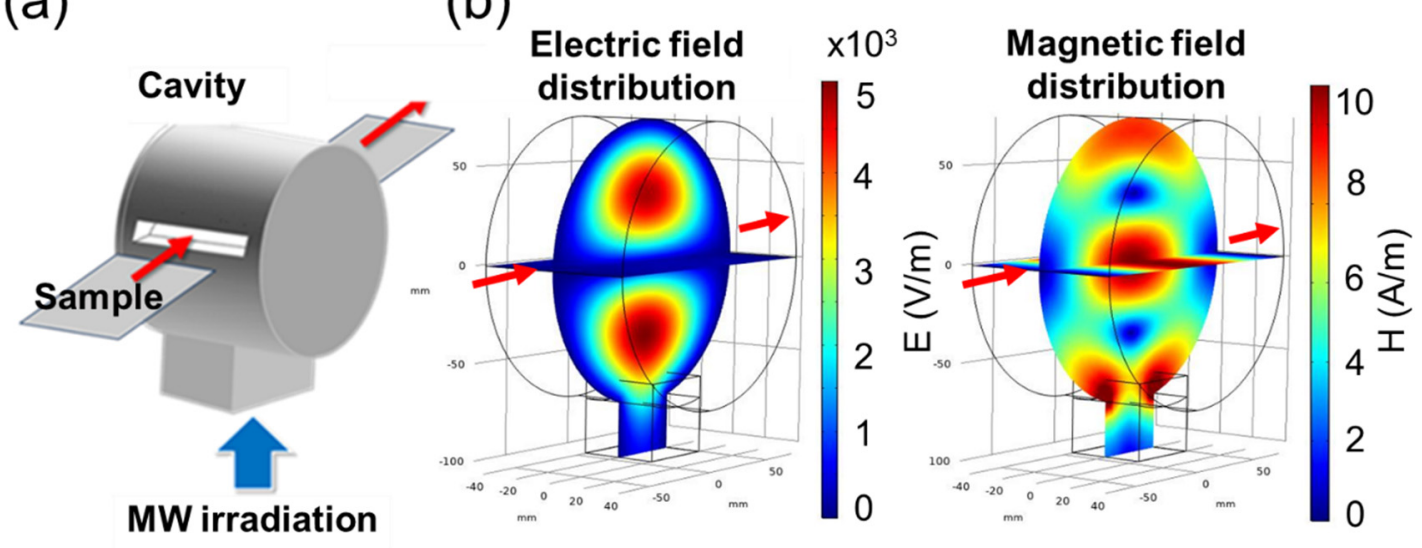

Figure 3. (a) Induction soldering system of MW and (b) the simulated distribution of electric and magnetic fields in the $\mathrm{TM}_{110}$ cavity. The frequencies of the simulations are $2.4446 \mathrm{GHz}$. Red arrows are sample conveying direction.

\subsection{MW Sintering Properties and Morphology of Solder Paste}

Figure 4 shows the temperature dependency with respect to output power of MW. Furthermore, infrared (IR) camera images are shown in Figure 5. The temperatures of the samples under MW irradiation at 1 and $5 \mathrm{~W}$ for $70 \mathrm{~s}$ were less than $100{ }^{\circ} \mathrm{C}$ and the solder paste did not melt (Figure S1a,b). In contrast, the temperatures of the samples heated at 10,20 , and $30 \mathrm{~W}$ exceeded $140{ }^{\circ} \mathrm{C}$ and the samples melted, leading to the formation of balls, as shown in Figure S1c,d. The formation of balls would mean insufficient wetting of the polyimide substrate by the molten solder paste. The sample heated by a $10-\mathrm{W}$ output power took $15 \mathrm{~s}$ to melt, whereas the samples subjected to 20 and $30 \mathrm{~W}$ of output power took about $10 \mathrm{~s}$ to melt. In the process of induction soldering by MW at 10, 20, and $30 \mathrm{~W}$ output powers, the temperature increased dramatically from around $110^{\circ} \mathrm{C}$. This would be because of the evaporation process of the solvent contained in the solder paste, because no endothermic process was observed at around $110^{\circ} \mathrm{C}$ in the TG/TDA and DSC measurements (Figure S2). After reaching around $150{ }^{\circ} \mathrm{C}$, the temperature decreased. This decrease in temperature after the melting process would be because (i) melted balls were formed and the balls would reflect MW $[14,17,18]$ and/or (ii) penetration depth decreased with an increase in conductivity [24], and eddy current was not generated.

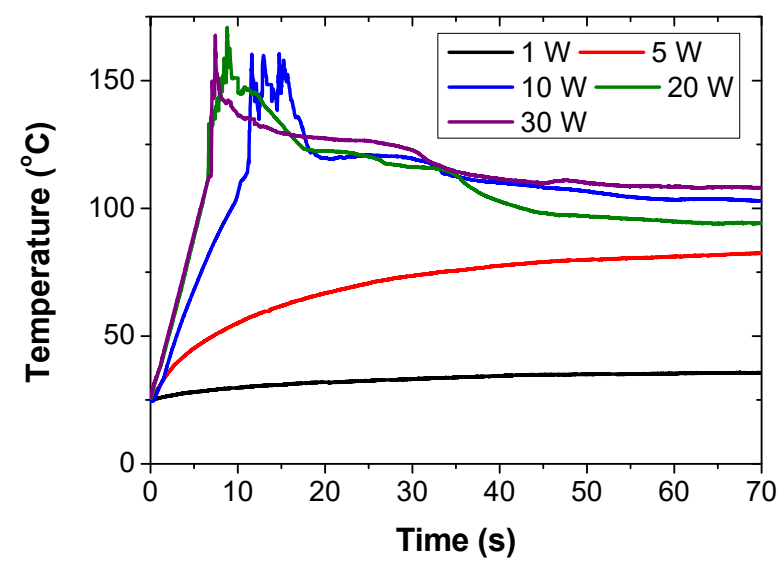

Figure 4. Changes in temperature of solder paste on a polyimide sheet by MW irradiation at 1, 5, 10, 20, and $30 \mathrm{~W}$ output powers for $70 \mathrm{~s}$. 


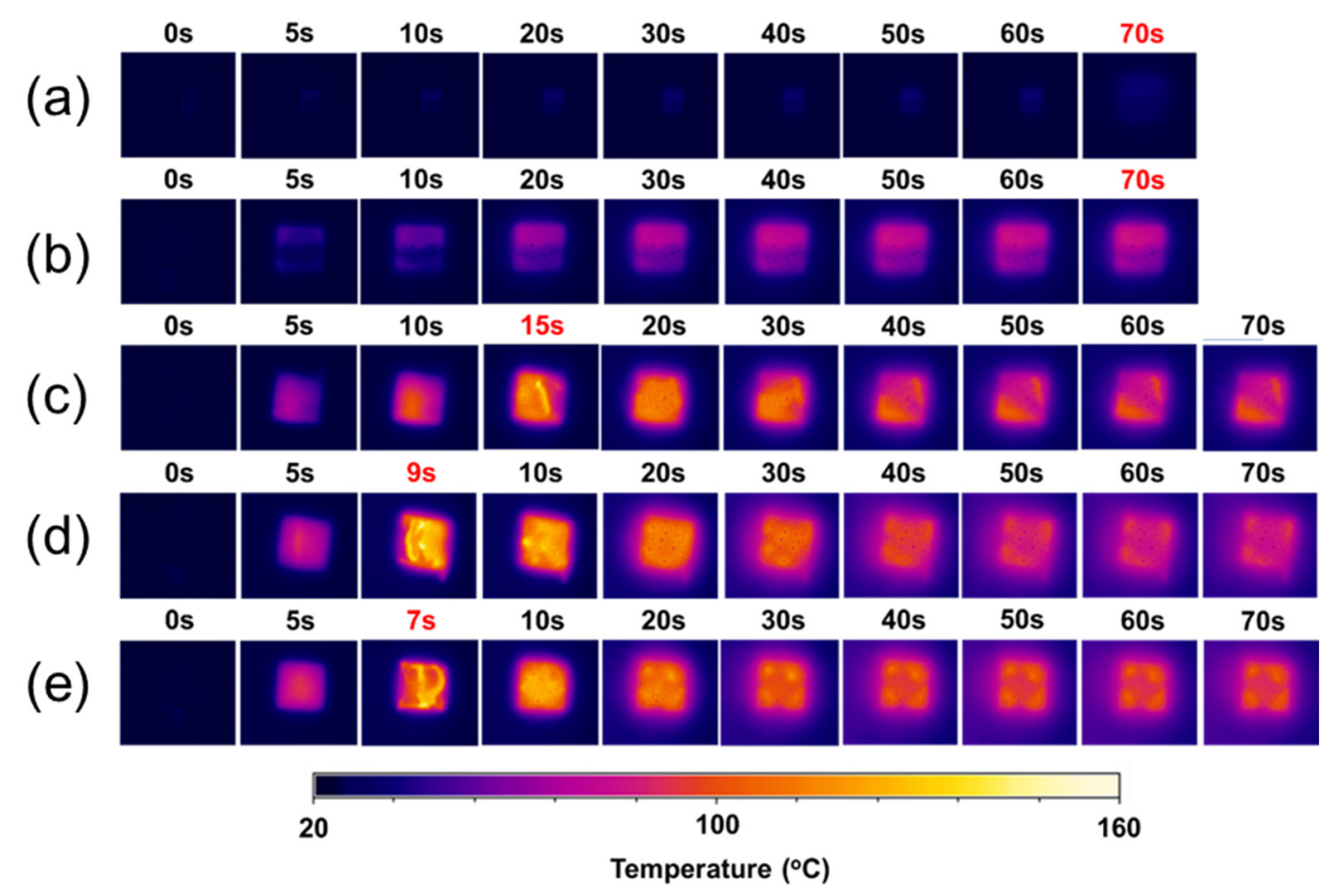

Figure 5. Infrared (IR) thermal imaging of solder paste on a polyimide sheet by MW irradiation with (a) 1, (b) 5, (c) 10, (d) 20, and (e) $30 \mathrm{~W}$ output powers for $70 \mathrm{~s}$. Red characters indicate the times of maximum temperature during the heating process.

\subsection{Thermal Property of Silver Pad Patterns by the Induction Soldering of MW}

Figure 6 and Table S1 show the temperature difference $(\Delta T)$ between initial temperature $\left(T_{0}\right)$ and arrived temperature (T) of the samples by the induction soldering of $\mathrm{MW}$ and $\Delta \mathrm{T}$, as defined in the below equation:

$$
\Delta \mathrm{T}=\mathrm{T}-\mathrm{T}_{0}
$$

$\Delta \mathrm{T}$ of $(1 \mathrm{~mm}, 0.5-20 \mathrm{~mm})$ samples $\left(\Delta \mathrm{T}_{(1,0.5-20)}\right)$ by the induction soldering of $\mathrm{MW}$ at $1,5,10,20$, $30 \mathrm{~W}$ of output power for $30 \mathrm{~s}$ were less than $10^{\circ} \mathrm{C}$, as shown in Figure $6 \mathrm{a}$ and Table S1; $\triangle \mathrm{T}_{(1,0.5-20)}$ $=0.2-0.8^{\circ} \mathrm{C}$ for $1 \mathrm{~W}, 1.1-1.5^{\circ} \mathrm{C}$ for $5 \mathrm{~W}, 1.7-2.6^{\circ} \mathrm{C}$ for $10 \mathrm{~W}, 3.3-5.5^{\circ} \mathrm{C}$ for $20 \mathrm{~W}$, and $5.3-8.6^{\circ} \mathrm{C}$ for $30 \mathrm{~W}$, respectively. These results suggest that $\Delta \mathrm{T}$ is not mainly dependent on the length of samples. To elucidate the low $\Delta \mathrm{T}$ reason, the simulation of magnetic field distribution around bulk silver in the cavity was performed by using $\mathrm{COMSOL}^{\circledR}$ software (Figure 7). Figure 7 a shows the magnetic field distribution of conveying sample which is $\mathrm{z}$ axis $=0$ in the cavity without sample, while Figure $7 \mathrm{~b}, \mathrm{c}$ show magnetic field distribution in the cavity with samples whose thickness are $8 \mu \mathrm{m}$. A square size drawn with a solid line in Figure $7 \mathrm{a}$ is $20 \mathrm{~mm}$ in width $\times 20 \mathrm{~mm}$ in length whose length is within the sample size. In particular, the penetration depth of bulk silver, which was estimated by the equation [24] was $1.3 \mu \mathrm{m}$. The magnetic field distribution intensities around the bulk silver samples, which are (width, length) $=(1 \mathrm{~mm}, 5 \mathrm{~mm}),(1 \mathrm{~mm}, 10 \mathrm{~mm}),(1 \mathrm{~mm}, 15 \mathrm{~mm})$, and $(1 \mathrm{~mm}, 20 \mathrm{~mm})$, are almost the same as those shown in Figure $7 \mathrm{~b}$. This is because the direction of magnetic field vibration is the same with the direction of length and the magnetic field intensity decreases from the center to length direction [25-27]. Therefore, the samples do not have the possibility to absorb MW effectively, even if the sample length increases. In general, magnetic field induces the circular electrical current, which called eddy current and the eddy current also induces Joule heat, leading to a temperature increase in the sample [24]. Due to low eddy current, which is induced by low magnetic field intensity, the generation of Joule heat is also low. Therefore, the $\Delta \mathrm{T}_{(1,5-20)}$ would be also low. 
(a)

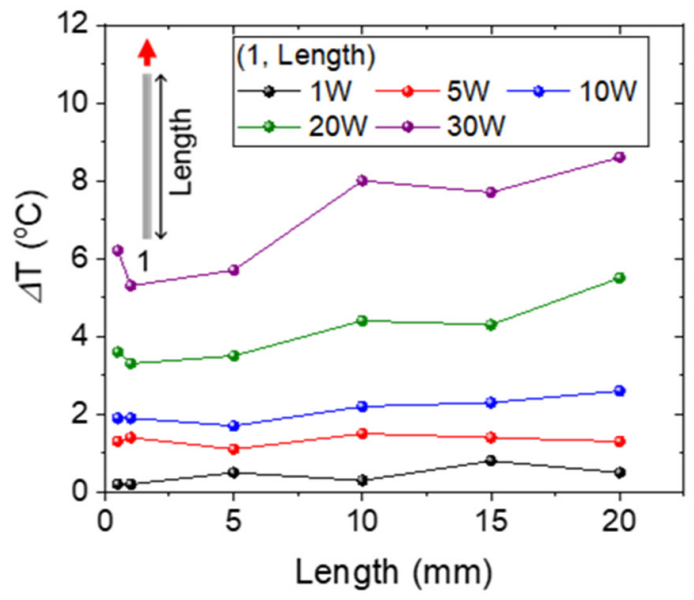

(b)

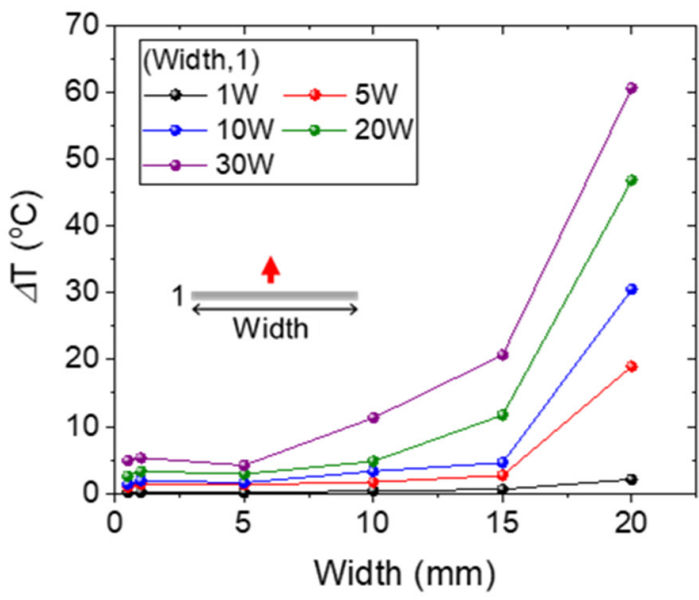

Figure 6. (a) $\Delta \mathrm{T}_{(1,0.5)}, \Delta \mathrm{T}_{(1,1)}, \Delta \mathrm{T}_{(1,5)}, \Delta \mathrm{T}_{(1,10)}, \Delta \mathrm{T}_{(1,15)}, \Delta \mathrm{T}_{(1,20)},\left(\right.$ b) $\Delta \mathrm{T}_{(0.5,1)}, \Delta \mathrm{T}_{(1,1)}, \Delta \mathrm{T}_{(5,1)}, \Delta \mathrm{T}_{(10,1)}$, $\Delta \mathrm{T}_{(15,1)}$, and $\Delta \mathrm{T}_{(20,1)}$ by MW irradiation at $1,5,10,20,30 \mathrm{~W}$ output powers for $30 \mathrm{~s}$, respectively. Inset images are the sample shape. The red arrows of inset are the direction of conveying the samples.

(a)

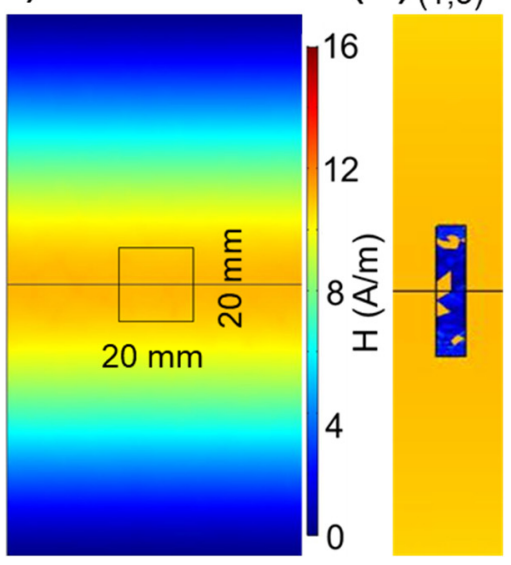

(b)
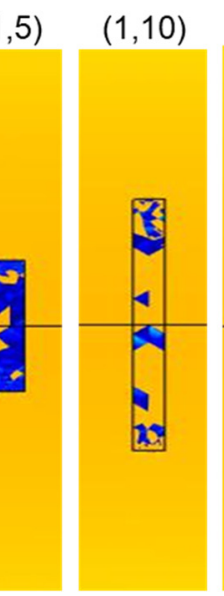

$(1,15)$

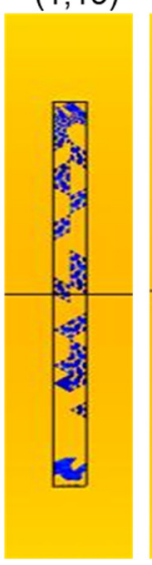

(c)
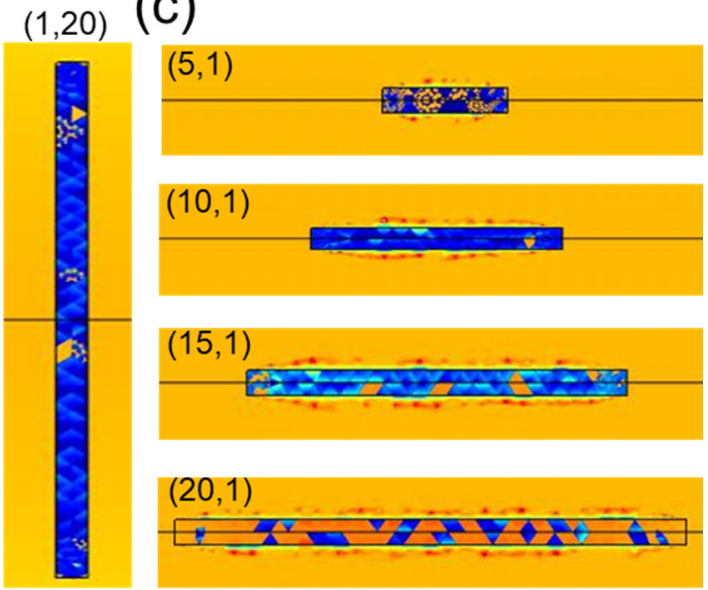

Figure 7. Simulation of magnetic field distribution around bulk silver against the direction of conveying the samples in the $\mathrm{TM}_{110}$ cavity: (a) empty cavity, (b) (width, length) $=(1 \mathrm{~mm}, 5 \mathrm{~mm}),(1 \mathrm{~mm}, 10 \mathrm{~mm})$, $(1 \mathrm{~mm}, 15 \mathrm{~mm}),(1 \mathrm{~mm}, 20 \mathrm{~mm}),(\mathbf{c})(5 \mathrm{~mm}, 1 \mathrm{~mm}),(10 \mathrm{~mm}, 1 \mathrm{~mm}),(15 \mathrm{~mm}, 1 \mathrm{~mm})$, and $(20 \mathrm{~mm}, 1 \mathrm{~mm})$ bulk silver with $8 \mu \mathrm{m}$ of thickness, respectively.

On the other hand, the $\Delta \mathrm{T}$ of samples $\left(\Delta \mathrm{T}_{(0.5-20,1)}\right)$ by the induction soldering of $\mathrm{MW}$ at $1,5,10,20$, $30 \mathrm{~W}$ output powers for $30 \mathrm{~s}$ increased as an increase in both width and MW output power, as shown in Figure $6 \mathrm{~b}$ and Table $\mathrm{S} 1 ; \Delta \mathrm{T}_{(0.5-20,1)}=0.1-2.1{ }^{\circ} \mathrm{C}$ for $1 \mathrm{~W}, \Delta \mathrm{T}_{(0.5-20,1)}=1.0-19{ }^{\circ} \mathrm{C}$ for $5 \mathrm{~W}, \Delta \mathrm{T}_{(0.5-20,1)}$ $=1.4-30.5^{\circ} \mathrm{C}$ for $10 \mathrm{~W}$, and $\Delta \mathrm{T}_{(0.5-20,1)}=2.6-46.8^{\circ} \mathrm{C}$ for $20 \mathrm{~W}$, and $\Delta \mathrm{T}_{(0.5-20,1)}=4.2-60.6^{\circ} \mathrm{C}$ for $30 \mathrm{~W}$, respectively. As shown in Figure $7 \mathrm{a}, \mathrm{c}$, the magnetic field in the cavity was uniformly widespread at the $90^{\circ}$ angle direction against the sample conveying direction, and the magnetic field intensity around the bulk silver also increased with an increase in width [25-27]. The increase in magnetic field intensity around bulk silver accompanied with an increase in width would be caused by a uniform strong magnetic field along width direction and $90^{\circ}$ angle against the sample conveying direction [25-27]. Due to generation of higher eddy current associated with an increase in magnetic field intensity resulting from an increase in width, higher Joule heat, which is induced by eddy current, is generated with an increase in width and consequently $\Delta \mathrm{T}$ would increase [24]. To confirm this consideration, simulations of resistive loss around bulk silver with $8 \mu \mathrm{m}$ of thickness were carried out. As shown in 
Figure 8, resistive loss around the sample was concentrated with the edge of bulk silver. Furthermore, the resistive loss also increased with an increase in width, which also supports the notion that eddy current would increase with an increase in width. From the results of the magnetic field and resistive loss simulations of the bulk silver, an increase in temperature would be caused by an increase in magnetic field intensity and eddy current with an increase in width.
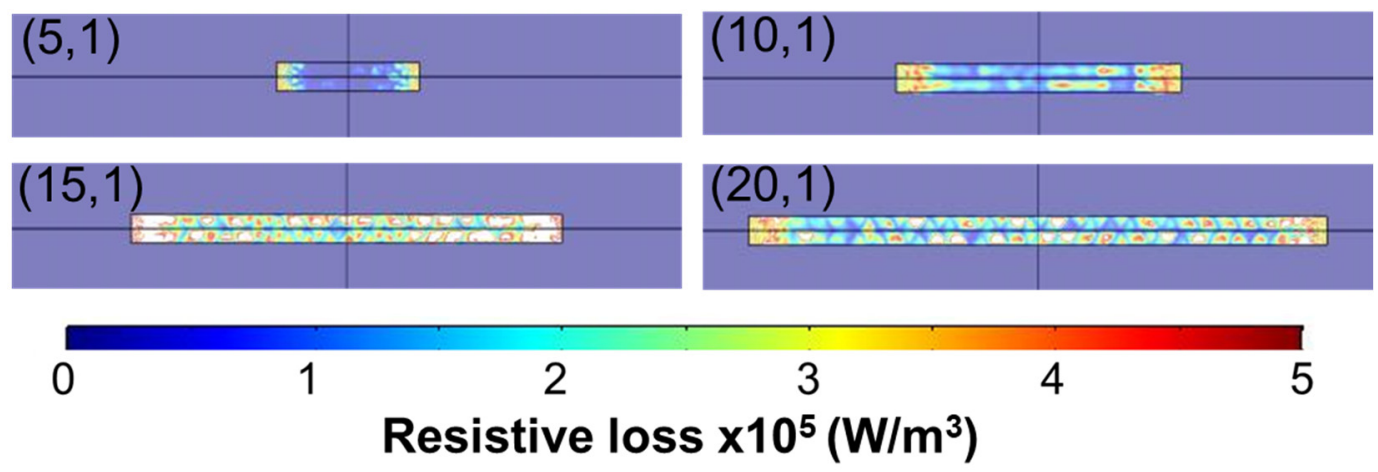

Figure 8. Simulation of resistive loss around bulk silver against the direction of conveying the samples in the $\mathrm{TM}_{110}$ cavity: (width, length) $=(5 \mathrm{~mm}, 1 \mathrm{~mm}),(10 \mathrm{~mm}, 1 \mathrm{~mm}),(15 \mathrm{~mm}, 1 \mathrm{~mm})$, and $(20 \mathrm{~mm}$, $1 \mathrm{~mm}$ ) bulk silver with $8 \mu \mathrm{m}$ of thickness, respectively.

\subsection{Mounting a Device on a Polyimide Sheet Using the MW Method}

We mounted a temperature sensor (SHT-31-DIS-B) on a polyimide substrate by MW irradiation (Figure 9). First, silver paste was spread on the polyimide sheet as an electric circuit using the screen-printing method, and the pattern was heated at $100{ }^{\circ} \mathrm{C}$ for $1 \mathrm{~h}$ on a hot plate. Second, solder paste was spread on the silver circuit to form a connection between the circuit and the sensor, and then a thermo-sensor was mounted on the silver pattern (Figure 9a). Figure 9b,c show the sensor and connection part between the silver circuit and sensor before and after MW irradiation with $10 \mathrm{~W}$ of output power for $10 \mathrm{~s}$, confirming that the solder paste melted and the sensor was connected to the electric circuit through the melted solder paste without damaging the substrate. In addition, as shown in the thermal image of the sample under MW irradiation with $10 \mathrm{~W}$ of output power for $10 \mathrm{~s}$ (Figure $9 \mathrm{~d}$ ), the temperature of the sensor part increased rapidly and reached $\sim 160{ }^{\circ} \mathrm{C}$ for $11 \mathrm{~s}$, whereas the temperature of the silver electric circuit did not increase during the MW irradiation. This is because the reaction area (area of solder paste containing sensor unit) is larger than the silver electric circuit and the width of the electric circuit was less than $6 \mathrm{~mm}$ against magnetic field direction, leading to effective solder heating and melting by MW. Figure 9e shows the temperature dependency with respect to various output powers of MW irradiation. The results confirm that the solder melted under 5-30 W of output power, similar to the results of Figure 9c, after the temperature had exceeded $150{ }^{\circ} \mathrm{C}$. In the process of heating only solder paste by MW, the temperature of the solder paste dramatically decreased after reaching around $150{ }^{\circ} \mathrm{C}$ during the induction soldering by $\mathrm{MW}$ (Figure 5), while, in the process of mounting a device by MW, the temperature decrease of the solder paste was not observed after reaching $160^{\circ} \mathrm{C}$ (Figure 9e). The reasons would be as follows. The melting and adherence between the solder and the sensor (Figure 9c) would occur without the formation of a small ball, leading to the generation of higher eddy current than the process of heating only solder. In addition to this, dielectric substances and metals in the sensor would also absorb MW and heat up with the generation of eddy current.

Finally, we checked the room temperature using the thermo-sensor mounted by MW irradiation to confirm that the device works well and that neither the sensor nor the silver electric circuit had been damaged by MW irradiation. The room temperature values measured by the commercial digital thermometer and the SHTDA-2 sensor were 23.4 and $24.6^{\circ} \mathrm{C}$, as summarized in Table 1 . The room temperature measured by the sensor mounted using MW was $24.8^{\circ} \mathrm{C}$. These results indicate that the 
thermo-sensor mounted by MW works well and did not suffer any damage from induction soldering by MW. On the other hand, we also succeeded in mounting a thermo-sensor on polyethylene terephthalate film (PET) by the induction soldering of MW without any damage to the sensor and PET. Their detail results would be report elsewhere.

(a)

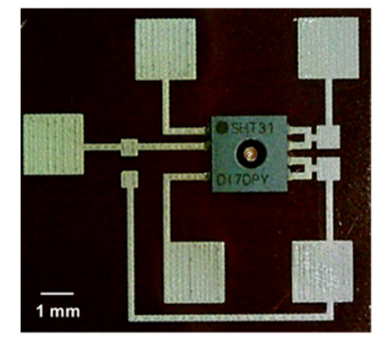

(b)

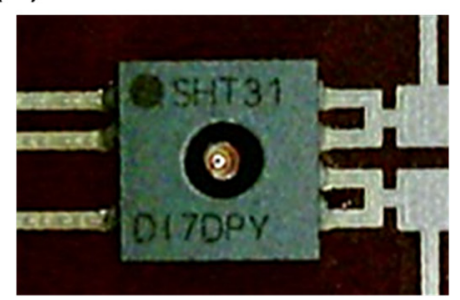

(d)

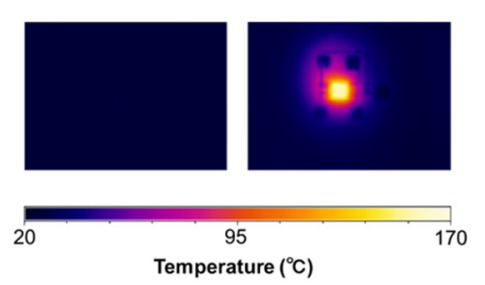

(c)

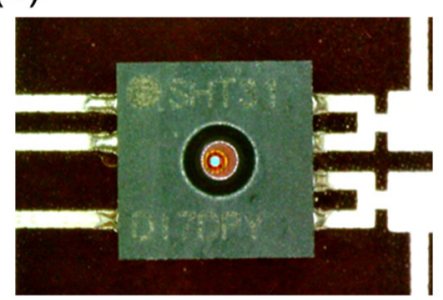

(e)

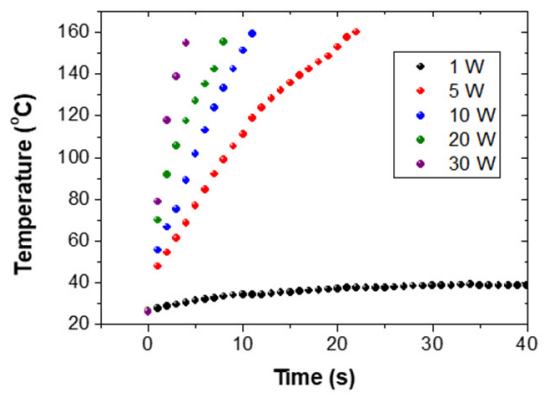

Figure 9. (a) Image of a thermo-sensor. Photographs of a sensor and connection part (b) before and (c) after MW irradiation at $10 \mathrm{~W}$ of output power. (d) Thermography of samples by MW irradiation with $10 \mathrm{~W}$ of output power for $10 \mathrm{~s}$. (e) Temperature properties by MW irradiation with 1 (black circle), 5 (red circle), 10 (blue circle), 20 (green circle), and $30 \mathrm{~W}$ (purple circle) output powers for 40, 22, 11, 8, and $4 \mathrm{~s}$, respectively.

Table 1. Room temperate measured by digital meter and sensors.

\begin{tabular}{lcc}
\hline \multicolumn{1}{c}{ Temperature Sensor } & Voltage $(\mathbf{V})$ & Temperature $^{\mathbf{b}}\left({ }^{\circ} \mathbf{C}\right)$ \\
\hline Digital meter & - & 23.4 \\
\hline SHTDA-2 & 1.6158 & 24.6 \\
\hline SHT-31-DIS-B $^{\text {a }}$ & 1.6210 & 24.8
\end{tabular}

a A sensor which was mounted by induction soldering of MW. ${ }^{\mathrm{b}}$ Calculated as (output voltage $\left.\times 1000 / 25\right)-40$.

\section{Conclusions}

We have developed an MW reactor system with a cylindrical single mode $\mathrm{TM}_{110}$ cavity that separates the electric fields at the top and bottom and a magnetic field at the center in the cavity. The system enables the heating of electrodes with silver paste and the melting of solder paste. In the investigation of the temperature properties of the electrodes by MW, we found that temperature increase was mainly dependent on not the length but width of the electrode and was higher if there 
was an increase in the width of electrodes. In the simulation of magnetic field distribution by using COMSOL ${ }^{\circledR}$ software (version 5.4, COMSOL Inc., Boston, MA, USA, 2018), magnetic field intensity around samples also increased with an increase in width, while magnetic field intensity around samples did not increase when the length was large. When the width of the sample was large, the increase in magnetic field around the sample in simulation was because magnetic field distribution is uniformly widespread at the $90^{\circ}$ direction of the conveying the samples. For this reason, we found that the temperature increase of the samples highly depends on the width of the sample, which corelated with magnetic field intensity and eddy current value. Furthermore, we successfully mounted a temperature sensor on a polyimide substrate, without damaging the sensor device or the substrate, using MW for a short time period (10 s) and a low output power $(10 \mathrm{~W})$; the temperature of the substrate was less than $100{ }^{\circ} \mathrm{C}$ during induction soldering by MW and the substrate surface in a microscope image was not changed by MW. Comparisons with a commercial digital thermometer and thermo-sensor show that the mounted temperature sensor device works well, suggesting that induction heating by MW can be applied during the mounting process instead of conventional reflow heating. The developed MW system, the investigation of electrode pad shape effect on induction heating by MW, and the mounting process of electric components by MW should be further developed for use in electronics' packaging.

Supplementary Materials: The following are available online at http://www.mdpi.com/2227-9717/8/5/557/s1, Figure S1: (a) A photograph and (b) an optical image of solder paste before MW heating process on polyimide sheet. (c) A photograph and (d) an optical image of solder paste after MW heating process on polyimide sheet,

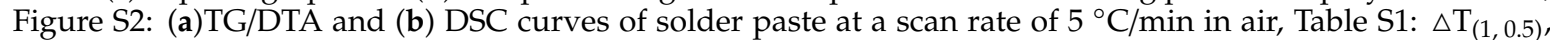

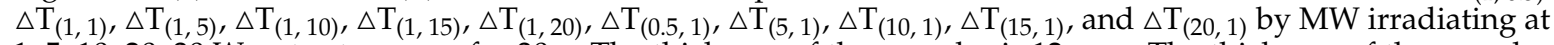
$1,5,10,20,30 \mathrm{~W}$ output powers for $30 \mathrm{~s}$. The thickness of the samples is $12 \mathrm{~mm}$. The thickness of the samples is $12 \mathrm{~mm}$, Table S2: Information about number of elements, meshfree time, and solution time of magnetic field distribution in simulation using Comsol Multiphysics ${ }^{\circledR}$ software.

Author Contributions: K.K., T.N., M.N., and S.U. conceived and designed the experiments; K.K. performed the experiments; K.K. and S.U. analyzed the data; K.K. wrote the paper; K.K., T.N., M.N., and S.U. reviewed and edited the paper; S.U. supervised the research. All authors have read and agreed to the published version of the manuscript.

Funding: This research received no external funding.

Conflicts of Interest: The authors declare no conflict of interest.

\section{References}

1. Alaa, M.; Zaidan, A.; Zaidan, B.; Talal, M.; Kiah, M. A review of smart home applications based on Internet of Things. J. Netw. Comput. Appl. 2017, 97, 48-65. [CrossRef]

2. Liu, Y.; Wang, H.; Zhao, W.; Zhang, M.; Qin, H.; Xie, Y. Flexible, Stretchable Sensors for Wearable Health Monitoring: Sensing Mechanisms, Materials, Fabrication Strategies and Features. Sensors 2018, 18, 645. [CrossRef] [PubMed]

3. Parrilla, M.; Cuartero, M.; Crespo, G.A. Wearable potentiometric ion sensors. TrAC Trebds Anal. Chem. 2019, 110, 303-320. [CrossRef]

4. Acome, E.; Mitchell, S.K.; Morrissey, T.G.; Emmett, M.B.; Benjamin, C.; King, M.; Radakovitz, M.; Keplinger, C. Hydraulically amplified self-healing electrostatic actuators with muscle-like performance. Science 2018, 359, 61-65. [CrossRef] [PubMed]

5. Ammar, M.; Russello, G.; Crispo, B. Internet of Things: A survey on the security of IoT frameworks. J. Inf. Secur. Appl. 2018, 38, 8-27. [CrossRef]

6. Pan, J.; McEIhannon, J. Future Edge Cloud and Edge Computing for Internet of Things Applications. IEEE Internet Things J. 2018, 5, 439-449. [CrossRef]

7. Abtew, M.; Selvaduray, G. Lead-free solders in microelectronics. Mater. Sci. Eng. Rep. 2000, $27,95-141$. [CrossRef]

8. Suganuma, K.; Kim, S.J.; Kim, K.S. High-temperature lead-free solders: Properties and possibilities. JOM 2009, 61, 64-71. [CrossRef]

9. Li, Y.; Wong, C.P. Recent advances of conductive adhesives as a lead-free alternative in electronic packaging: Materials, processing, reliability and applications. Mater. Sci. Eng. R 2006, 51, 1-35. [CrossRef] 
10. Santos, E.C.; Shiomi, M.; Osakada, K.; Laoui, T. Rapid manufacturing of metal components by laser forming. Int. J. Mach. Tools Manuf. 2006, 46, 1459-1468. [CrossRef]

11. Gu, D.D.; Meiners, W.; Wissenbach, K.; Poprawe, R. Laser additive manufacturing of metallic components: Materials, processes and mechanisms. Int. Mater. Rev. 2012, 57, 133-164. [CrossRef]

12. Lee, W.H.; Seong, J.G.; Yoon, Y.H.; Jeong, C.H.; Van Tyne, C.J.; Lee, H.G.; Chang, S.Y. Synthesis of TiC reinforced Ti matrix composites by spark plasma sintering and electric discharge sintering; a comparative assessment of microstructural and mechanical properties. Ceram. Int. 2019, 45, 8108-8114. [CrossRef]

13. Mishra, R.R.; Sharma, A.K. Microwave-material interaction phenomena: Heating mechanisms, challenges and opportunities in material processing. Compos. Part A 2016, 81, 78-97. [CrossRef]

14. Khaled, D.E.; Novas, N.; Gazquez, J.A.; Manzano-Agugliaro, F. Microwave dielectric heating: Applications on metals processing. Renew. Sustain. Energ. Rev. 2018, 82, 2880-2892. [CrossRef]

15. Zou, Y.; Li, C.H.; Liu, J.A.; Wu, J.M.; Hu, L.; Gui, R.F.; Shi, Y.S. Towards fabrication of high-performance $\mathrm{Al}_{2} \mathrm{O}_{3}$ ceramics by indirect selective laser sintering based on particle packing optimization. Ceram. Int. 2019, 45, 12654-12662. [CrossRef]

16. Chaim, R.; Levin, M.; Shlayer, A.; Estournes, C. Sintering and densification of nanocrystalline ceramic oxide powders: A review. Adv. Appl. Ceram. 2008, 107, 159-169. [CrossRef]

17. Mirzaei, A.; Neri, G. Microwave-assisted synthesis of metal oxide nanostructures for gas sensing application: A review. Sens. Actuators B Chem. 2016, 237, 749-775. [CrossRef]

18. Loharkar, P.K.; Ingle, A.; Jhavar, S. Parametric review of microwave-based materials processing and its applications. J. Mater. Res. Technol. 2019, 8, 3306-3326. [CrossRef]

19. Levin, E.E.; Grebenkemper, J.H.; Pollock, T.M.; Seshadri, R. Protocols for High Temperature Assisted-Microwave Preparation of Inorganic Compounds. Chem. Mater. 2019, 31, 7151-7159. [CrossRef]

20. Thomas-Hillman, I.; Laybourn, A.; Dodds, C.; Kingman, S.W. Realising the environmental benefits of metal-organic frameworks: Recent advances in microwave synthesis. J. Mater. Chem. A 2018, 6, 11564-11581. [CrossRef]

21. Horikoshi, S.; Osawa, A.; Abe, M.; Serpone, N. On the generation of hot-spots by microwave electric and magnetic fields and their impact on a microwave-assisted reaction in the presence of metallic Pd nanoparticles on an activated carbon support. J. Phys. Chem. C 2011, 115, 23030-23035. [CrossRef]

22. Nishioka, M.; Miyakawa, M.; Kataoka, H.; Koda, H.; Sato, K.; Suzuki, T.M. Continuous synthesis of monodispersed silver nanoparticles using a homogeneous heating microwave reactor system. Nanoscale 2011, 3, 2621-2626. [CrossRef] [PubMed]

23. Miyakawa, M.; Hiyoshi, N.; Koda, H.; Watanabe, K.; Kunigami, H.; Kunigami, H.; Miyazawa, A.; Nishioka, M. Continuous syntheses of carbon-supported Pd and Pd@Pt core-shell nanoparticles using a flow-type single-mode microwave reactor. RSC Adv. 2020, 10, 6571-6575. [CrossRef]

24. Morgan, S.P., Jr. Effect of surface roughness on eddy current losses at microwave frequencies. J. Appl. Pnys. 1949, 20, 352-362. [CrossRef]

25. Webb, A. Cavity- and waveguide-resonators in electron paramagnetic resonance, nuclear magnetic resonance, and magnetic resonance imaging. Prog. Nucl. Magn. Reson. Spectrosc. 2014, 83, 1-20. [CrossRef]

26. Verhoeven, W.; van Rens, J.F.M.; Kemper, A.H.; Rietman, E.H.; van Doorn, H.A.; Koole, I.E.; Kieft, R.; Mutsaers, P.H.A.; Luiten, O.J. Design and characterization of dielectric filled $\mathrm{TM}_{110}$ micraowave cavities for ultrafast electron microscopy. Rev. Sci. Instrum. 2019, 90, 080370. [CrossRef]

27. Cao, Z.; Yoshikawa, N.; Taniguchi, S. Directional selectivity of microwave H field heating of Au thin films and non-doped Si plates. Mater. Chem. Phys. 2009, 117, 14-17. [CrossRef]

(C) 2020 by the authors. Licensee MDPI, Basel, Switzerland. This article is an open access article distributed under the terms and conditions of the Creative Commons Attribution (CC BY) license (http://creativecommons.org/licenses/by/4.0/). 